\title{
STUDI KASUS: TERAPI BERMAIN MEMFASILITASI PERUBAHAN PERILAKU MENOLAK SEKOLAH
}

\author{
Monica Sri Sunaringsih, Linda Wati \\ ${ }^{1}$ Magister Profesi Psikologi Klinis, Universitas Tarumanagara, Jakarta \\ Email: monica.717172006@stu.untar.ac.id \\ ${ }^{2}$ Magister Profesi Psikologi Klinis, Universitas Tarumanagara, Jakarta \\ Email:lindaw@fpsi.untar.ac.id
}

\begin{abstract}
ABSTRAK
Perilaku menolak sekolah, adalah perilaku yang umum dialami anak-anak dalam masa sekolah, dengan berbagai alasan. Perilaku ini tidak selalu menjadi diagnosa patologis, tapi pada praktisnya kerap menyebabkan stres dalam keluarga. Saat anak memiliki keinginan untuk tidak hadir di sekolah, mereka cenderung berperilaku maladaptif. ChildCentered Play Therapy (CCPT) dipandang sebagai bentuk intervensi terapetik yang tidak berfokus pada permasalahan anak secara langsung, tetapi memberikan ruang dan kesempatan pada anak untuk memproses masalahnya. CCPT terbukti dapat mengatasi berbagai masalah perilaku dalam perkembangan anak hingga remaja. Namun, belum banyak ulasan mengenai bagaimana CCPT memfasilitasi perubahan perilaku tersebut. Penelitian ini bertujuan memberikan informasi baru mengenai efektivitas CCPT dalam mengubah perilaku anak terhadap sekolah. Subjek penelitian ini adalah anak perempuan berusia 6 tahun. Penelitian qualitative, single case study ini memberikan penjelasan proses perubahan/ transformasi perilaku partisipan secara intensif dan deskriptif dalam 18 sesi terapi individual. Play Therapy Dimensional Model (PTDM) dalam level consiousness-unconsiousness dan directive-nondirectiveness akan mendeskripsikan arah pergerakan dan perubahan perilaku partisipan dalam proses terapi. Hasil penelitian berbentuk laporan observasi peneliti, dokumentasi sesi, dan laporan orangtua menunjukkan keselarasan terhadap perubahan perilaku partisipan. Perubahan perilaku sesuai dengan tujuan CCPT dan sesuai dengan harapan orangtua. Partisipan hadir di sekolah, berani menampilkan dirinya di depan kelas, dan perilaku somatis sirna.
\end{abstract}

Kata kunci: child-centered play therapy, school refusal behavior, play therapy dimensional model

\section{ABSTRACT}

School refusal is a behavior commonly found in school age children, with various reasons. This behavior is not always a pathological diagnosis, however, in practice it often causes stress in the family. When children refuse to attend school, they tend to behave maladaptively. Child-Centered Play Therapy (CCPT) is seen as a form of therapeutic intervention that does not focus on children's problems directly, but it gives children space and opportunity to process their problem. CCPT is proven to be able to treat various behavioral problems in the development of children to adolescents. However, there are not many reviews about how CCPT facilitates this behavioral change. This study aims to provide new information about the effectiveness of CCPT in changing children's behavior towards school. The sole subject of this study was a 6-year-old girl. This qualitative, single case study provides an explanation of the process of change / transformation of participant's intensive and descriptive behavior in 18 individual therapy sessions. Play Therapy Dimensional Model (PTDM) at the level of consciousness-unconsiousness and directivenondirectiveness will describe the direction of movement and changes in participant behavior during the therapy process. The result of the study was in the form of researchers' observation reports, session documentation, and parental reports show conformity with changes in participant behavior. Changes in behavior was in accordance with the goals of the CCPT and with expectations of the parents. Participant attended school, dared to present herself in front of the classroom, and somatic behavior disappeared.

Keywords: child-centered play therapy, school refusal behavior, dimensional play model therapy 


\section{PENDAHULUAN}

\section{Latar Belakang}

Terdapat berbagai alasan yang membuat sebagian anak menolak untuk bersekolah, misalnya dalam masa transisi dari Taman Kanak-Kanak (TK) ke tingkat Sekolah Dasar (SD) ataupun saat harus kembali bersekolah seusai libur panjang. Sekitar 25\% anak-anak pada rentang usia 5-6 tahun dan 10-11 tahun, menolak hadir di sekolah kendati anak-anak tersebut adalah anak yang cerdas. Sebagian anak menolak bersekolah tanpa alasan dan perlawanan, sedangkan sebagian lainnya akan memberikan berbagai alasan yang dapat menyebabkan kemarahan orangtua. Walaupun tidak selalu terkait dengan diagnosa patologis, tetapi fenomena ini pada praktisnya tidak sekadar menjadi masalah perilaku, tetapi juga masalah psikososial yang menyebabkan stres pada anak dan keluarga (raisingchildre.net.au, 2016; Young, 2017). Stres yang dialami oleh anak, disebabkan karena kesulitan dalam menginternalisasi dan mengeksternalisasi masalahnya (Kearney, Chapman \& Cook, 2005).

Sebagian besar perilaku menolak sekolah pada anak-anak disebabkan karena perasaan cemas (Kearney, 2006; Freemont, 2003), depresi, dan social phobia (Lingenfelter \& Hartung, 2015). Child-Centered Play Therapy (CCPT) terbukti efektif dalam membantu anak yang memiliki berbagai masalah kecemasan dan meningkatkan perilaku prososial anak di sekolah (Lok, 2016; Frankel, 2018). Namun, penelitian studi kasus dalam psikologis klinis dapat memberikan penjelasan tentang kondisi individu secara rinci (Hanurawan, 2016).

\section{Perilaku Menolak Sekolah}

Perilaku menolak sekolah dipandang sebagai representasi ketidakmampuan anak untuk berfungsi sebagaimana yang diharapkan pada tahap perkembangannya, dalam konteks sekolah, atau kesulitan anak untuk beradaptasi terhadap berbagai faktor stres yang ada di lingkungan sekolah. Perilaku menolak sekolah (school refusal behavior) adalah sebuah fenomena dimana anak menunjukkan berbagai perilaku maladadaptif yang didasari oleh keinginan untuk tidak hadir di sekolah. Perilaku maladaptif yang tampak umumnya adalah kemelekatan, tidak patuh, menentang, dan perilaku manipulatif, misalnya cemas, tantrum, tangisan dan keluhan psikosomatis (Kearney \& Albano, 2007).

Pada rentang usia lima hingga sembilan tahun, perilaku menolak untuk hadir di sekolah umumnya disebabkan karena Separation Anxiety Disorder (SAD) (53.7\%), tanpa diagnosa (22.2\%), Generalized Anxiety Disorder (GAD) (9.3\%), Specific Phobia (9.3\%), Social Phobia/Avoidant Disorder (3.7\%), dan Enuresis (1.9\%) (Kearney, Chapman \& Cook, 2005). Diperkirakan, 18\% anak-anak berusia 6-17 tahun di Queensland Australia, mengalami gangguan kecemasan dan sebagian lainnya mengalami kecemasan yang tidak spesifik (Costello \& Angold, 1995; in Campbell, 2007). Kecemasan adalah salah satu bentuk emosi universal yang muncul sebagai respon biologis terhadap fungsi otak, saat menghadapi atau menghindari stimulus yang berbahaya. Pada anak-anak, kecemasan 'normal' dan 'patologis' sulit untuk dibedakan. Cemas dapat menjadi kondisi patologis, jika kecemasan tersebut menyebabkan seseorang tidak dapat menjalankan fungsi sebagaimana seharusnya (Beesdo, Knappe, \& Pine, 2009).

Keinginan untuk menghindari perasaan negatif dan/atau untuk mendapatkan perhatian, adalah alasan yang umum ditemukan pada anak-anak di Amerika berusia 5-17 tahun untuk tidak hadir di sekolah (Kearney \& Albano, 2007). Faktor eksternal seperti konflik dalam keluarga, perpindahan sekolah atau tempat tinggal, bullying juga berpotensi menjadi penyebab timbulnya perilaku menolak sekolah (raisingchildre.net.au, 2016; Bean, 2018; Busman, 2018). Apapun penyebabnya, jika diabaikan perilaku menolak sekolah dapat menyebabkan masalah sosial-emosional dan masalah pendidikan (Fremont, 2003; in Lingenfelter \& Hartung, 2015). Oppositional Defiant Disorder (ODD), Attention Deficit-Hyperactive Disorder (AD/HD), dan gangguan belajar spesifik juga dapat menjadi faktor penyebab perilaku menolak sekolah (Kearneyet al., 2005). 


\section{Terapi Bermain Child-Centered}

Play therapy is defined as a dynamic interpersonal relationship between a child and a therapist trained in play therapy procedures who provides selected play materials and facilitates the development of a safe relationship for the child to fully express and explore self(feelings, thoughts, experiences, and behaviors) through play, the child's natural medium of communication, for optimal growth and development (Landreth, 2002, p.16; in Schaefer, 2011).

Konsep person-centered therapy, mulanya dicetuskan oleh Carl Rogers, seorang humanistic psikoterapis yang menekankan pentingnya keberadaan seorang terapis atau konselor yang memiliki kesesuaian pada aspek perasaan, kesadaran, dan ekspresi diri dalam berempati (congruence), bersikap hangat, peduli, menerima klien sebagaimana adanya (unconditional positive regard), dan berfokus pada klien sepenuhnya dalam konteks waktu dan situasi saat ini (here and now) (Feist, Feist, \& Robert, 2009) atau mencari pola emosional dalam sesi, atau mengkombinasikan keduanya (Kottman, 2011; in Yasenik \& Gardner, 2012). Virginia Axline mengadaptasi konsep person-centered ke dalam child-centered play therapy, menurutnya, bermain adalah media yang alami bagi anak untuk mengekspresikan dirinya dan memberikan kesempatan pada anak untuk memproses perasaan dan masalahnya, sebagaimana orang dewasa menceritakan kesulitannya (Schaefer, 2011).

'A child's play is his talk, and the toys are his words' (Ginot, 1961; in Mullen \&Rickly, 2014). Saat bermain dalam lingkungan yang aman, anak-anak dapat mengekspresikan dirinya dengan bebas dan terapis memiliki kesempatan untuk memahami perspektif, perilaku, perasaan, dan pikiran anak (Killough-McGuire, \& McGuire, 2001; in Mullen and Rickly, 2014). Bermain memampukan anak-anak untuk bercerita tentang masalahnya, misalnya saat mereka merefleksikan perasaan, pikiran, dan konflik yang dialaminya melalui pilihan mainan yang tersedia (Kaduson \& Schaefer, 2006). Media bermain yang disarankan yaitu, miniatur figur yang merepresentasikan dunia nyata dan dunia imajinasi, pasir, media seni lukis dan keterampilan, tanah liat, playdough, boneka, rumah boneka, dan boneka tangan, topeng, musik, gerakan, berbagai macam kostum (Landreth, 2002, dalam Schaefer, 2011).

Terapis diharapkan dapat bersikap hangat dan menerima anak sebagaimana adanya, memberikan kesempatan pada anak untuk mengekspresikan dirinya dan merefleksikan perasaan anak, percaya bahwa anak memiliki kemampuan untuk menyelesaikan masalahnya, tidak berupaya untuk mempercepat proses terapi, dan memberikan batasan yang aman. Tujuan utama CCPT menurut Jennings (1999), adalah untuk membantu anak agar mampu menyembuhkan dirinya (self-healing) dan meningkatkan kesejahteraannya (well-being). Perubahan perilaku positif lainnya yang ditemukan oleh Sweeney dan Landreth (dalam Schaefer, 2003) yaitu, anak memiliki tanggung jawab, memiliki arah dan kontrol, mampu mengevaluasi, mandiri, mampu mengambil keputusan, merasa nyaman dengan dirinya, dan percaya diri.

\section{Play Therapy Dimensional Model}

Dalam sesi CCPT proses terapetik terjadi dalam dimensi level of consciousness-unconsiousness dan level of directiveness-non-directiveness. Setiap dimensi dapat dijelaskan dalam Play Therapy Dimensional Model (PTDM). Level of consciousness-unconsiousness menggambarkan kondisi kesadaran anak dalam proses terapi sedangkan level of directiveness-non-directiveness menggambarkanl level keterlibatan terapis dalam proses terapetik. PTDM memberikan jawaban pada pertanyaan 'siapa, apa, kapan, mengapa, dan bagaimana' dinamika proses terapetik terjadi. Pada dimensi non-directive terapis bermain mengikuti arahan permainan anak, sedangkan pada dimensi directive terapis lebih aktif dan direktif dalam prosesnya. Pada level unconsciousness anak mengekspresikan perasaannya menggunakan permainan yang bersifat metafor/simbolik, sedangkan pada level consciousness anak memiliki kesadaran penuh terhadap hal yang dipikirkan dan dirasakan dalam proses terapetik. 
Dalam kuadran $1(\mathrm{k} 1)$, terapis dapat lebih mudah mengenali masalah atau distorsi yang dialami anak, karena anak sepenuhnya memiliki kesadaran terhadap perasaan, pikiran, dan perilakunya. Misalnya, saat seorang anak memberikan identifikasi pada figur atau perannya dan meminta kita bermain bersama. Dalam kuadran $2(\mathrm{k} 2)$, terapis menginisiasi dan merancang akvitas bermain terkait dengan masalah yang dialami anak, misalnya kecemasan, self-control, agresi. Dalam area ini, melalui Structured play, terapis memiliki level direktif yang tinggi dan anak memiliki level kesadaran yang tinggi. Misalnya dalam aktivitas menggambar dengan instruksi yang bersifat direktif dan therapeutic board games. Dalam kuadran 3 (k3), terapis berperan sebagai reflektor perasaan dan emosi anak dalam proses terapetik, tanpa maksud untuk menginterpretasikannya refleksi yang tepat akan membantu anak mengekspresikan emosinya. Dalam kuadran $4(\mathrm{k} 4)$, terapis dapat mengelaborasi permainan sembari memberikan soft interpretation, komentar dan memvalidasi aksi dalam aktivitas bermain, dan menguji hipotesa. Aktivitas bermain dalam kuadran ini identik dengan permainan yang lebih bersifat fantasi dan simbolik. Dalam kuadran ini terapis dan anak stay in the play.

\section{Rumusan Masalah}

Penelitian studi kasus ini dilakukan dengan tujuan untuk memberikan penjelasan secara deskriptif tentang dinamika proses terapi dengan metode Child-Centered Play Therapy, pada seorang anak yang menolak bersekolah.

\section{METODE PENELITIAN}

\section{Karakteristik Partisipan}

Partisipan dalam penelitian ini adalah seorang anak perempuan tunggal, berinisial S (6 tahun 2 bulan/kelas Taman Kanak-Kanak tingkat B). S terpilih menjadi partisipan dalam penelitian ini, karena memiliki masalah perilaku menolak bersekolah yang sudah berlangsung selama kurang lebih 2 bulan. Perilaku menolak sekolah S tampak dalam bentuk pernyataan tidak mau sekolah, kemelekatan, kecemasan, menangis, dan terkadang somatis. S selalu menangis setiap malam sebelum tidur dan pagi hari sebelum berangkat sekolah. Kondisi ini menyebabkan Ibu dan Nenek yang mengasuhnya mengalami kelelahan emosional. Sejak usia S 4 tahun, ia akan menangis kalau ada orang yang tertawa ataupun memujinya. Tangan $S$ terasa dingin saat diminta untuk menjawab pertanyaan di kelas/di tempat umum. Saat ditanya oleh orang lain, $\mathrm{S}$ akan menunduk dan menjawab dengan suara yang sangat lirih. Beberapa bulan lalu, S diajak pergi berlibur oleh Nenek dalam waktu yang lama, dan S mendapatkan pembelajaran dari Guru, melalui media sosial. Sejak 2 bulan lalu, seusai libur panjang $S$ menolak untuk masuk sekolah berbagai alasan misalnya suara Guru-Guru di kelas bernada tinggi dan mengagetkannya, S merasa takut untuk melakukan kesalahan dan takut dimarahi oleh Guru. Selama ini, Ibu selalu memaksa S untuk tetap bersekolah tapi, saat pulang sekolah S tampak senang. Prestasi akademik S selalu diatas rata-rata kelas.

\section{Prosedur Penelitian / Pengumpulan Data}

Metode penelitian Qualitative, single case study digunakan untuk menjawab tujuan penelitian ini, yaitu untuk mendapatkan penjelasan secara intensif dan deskriptif tentang bagaimana CCPT memfasilitasi proses perubahan perilaku seorang anak perempuan yang menolak untuk sekolah, menjadi mau sekolah (Howitt, 2010). Peneliti dalam penelitian ini adalah seorang terapis bermain yang telah memiliki sertifikasi resmi dari asosiasi Play Therapy International (PTI). Dalam penelitian ini, peneliti berperan sebagai terapis yang memfasilitasi seluruh proses terapetik secara langsung. 
Secara prosedural, pihak referall telah mendapatkan penjelasan tentang bentuk CCPT dan memberikan persetujuan (informed consent) bahwa data dapat digunakan sebagai bahan penelitian ilmiah. Data penelitian terdiri dari (i) Dua kali wawancara dengan orangtua, dengan metode semistructured (tanpa verbatim), (ii) Pre-test dan post-test skor menggunakan alat ukur Strength and Difficulties Questionaires (SDQ), (iii) Komunikasi secara langsung maupun tidak langsung dengan orangtua melalui media whatsapp, (iv) Laporan observasi terapis (word.docx) tentang tema permainan, jenis mainan yang dipilih, aktivitas bermain yang dilakukan, serta pemahaman yang didapatkan oleh terapis, (v) Dokumentasi bentuk aktivitas bermain dalam bentuk foto (menggunakan kamera smartphone Iphone $X$ ) yang diambil setiap kalinya setelah sesi $C C P T$ berakhir.

Jadwal Pengambilan Data/ Hal-Hal Yang Mendukung dan Menghambat Pengambilan Data Sesi CCPT terdiri dari 18 sesi individual (45 menit/per sesi), dan diadakan 1x/minggu dalam ruangan terapi bermain di sebuah learning center. Sesi pertama dimulai pada awal Februari 2018, tetapi ada beberapa kondisi situasional (libur panjang sekolah, sakit, acara sekolah) yang menyebabkan seluruh rangkaian sesi special time selesai di bulan September 2018. Frekuensi pertemuan antara peneliti dan Ibu S cukup sering sehingga memudahkan terjadinya diskusi. Keterbatasan waktu antara sesi lainnya, menyebabkan peneliti tidak menuliskan semua hasil diskusi.

\section{Pedoman Observasi dan Wawancara / Instrumen Penelitian / Pengukuran}

Pedoman wawancara yang digunakan dalam penelitian ini adalah formulir standar Play Therapy International (Lampiran). Instrumen dalam penelitian ini adalah laporan observasi peneliti, dokumentasi sesi, alat ukur $S D Q$, dan laporan orangtua. Analisa terkait dengan aktivitas bermain dalam kerangka play therapy dimensional model, tema sesi dan/atau insight peneliti, perubahan perilaku S yang dapat diamati dan laporan orangtua. Selain untuk mengubah perilaku menolak sekolah, Ibu memiliki harapan agar $\mathrm{S}$ dapat lebih percaya diri, tidak terlalu sensitif (saat orang lain tertawa, tidak menangis), rasa cemas dan takutnya berkurang, dan memiliki rasa kompetitif.

\section{HASIL DAN PEMBAHASAN}

Sesi 1. Tampak ketegangan postur tubuh dan wajah S. Di awal sesi S tertarik pada bulu berwarna merah muda dan dengan sedikit arahan, S dapat mewujudkan angsa (k4). Kemudian S melepaskan agresifitasnya dengan karakter petinju yang memukuli kingkong (peneliti) dengan tenaga yang sangat kuat (k4). Peneliti melihat S memiliki konflik antara karakter angsa dan petinju. Sesi 2. S berproses menggunakan media pasir dalam keheningan dan tampak mengeluarkan tenaga yang sangat kuat (k3). Bermain boneka tanpa suara dan saat peneliti merefleksikan keheningannya, S berkata "sudah - sudah" dengan suara yang sendu (k3). Dalam karakter monyet, peneliti mengajarkan teknik relaksasi dan bertanya tentang keinginannya, tanpa suara S mengubah perannya menjadi burung yang terbang bebas $(\mathrm{k} 4)$. Peneliti melihat $\mathrm{S}$ mulai memiliki keberanian untuk mulai memproses konflik yang dialaminya. Sesi 3. S berbicara sebagai dokter memastikan semua boneka tangan yang ada sudah mendapatkan obat (k4). S menghabiskan waktu lama untuk membuat objek pertamanya dari tanah liat dan hanya dua menit bagi objek kedua, menurutnya mereka adalah 2 laki-laki (k3). Selesai sesi, Peneliti bertanya pada S siapakah yang membelikan baju yang di pakainya saat itu, dan jawabnya "Ayah".

Sebelum sesi keempat dimulai, Ibu S memberikan informasi bahwa S sudah tidak menangis saat malam hari dan tidak rewel kalau mau berangkat sekolah, dan kalau mengalami masalah akan berbicara dengan Ibunya. Bahkan S berani bertanya tentang Ayahnya. Perubahan lainnya adalah $\mathrm{S}$ berinisiatif memanggil Ayah barunya dengan sebutan Papa. Peneliti melihat $\mathrm{S}$ masih sulit untuk bersuara dengan jelas dan banyak menghindari tatapan mata langsung. Peneliti memfasilitasi 
komunikasi melalui permainan dan meminimalisasi tatap mata. S memproses kesulitannya yaitu konflik dalam dirinya melalui media art dan boneka tangan, dan memproses konsep Ayah dalam hidupnya secara simbolik melalui media tanah liat.

Sesi 4. S mewarnai kedua figur yang sudah dibuatnya pada sesi lalu dalam hening, figur yang pertama diwarnai adalah figur yang pertama dibuat oleh S (k3). S berperan sebagai dokter dan kali ini $\mathrm{S}$ memastikan semua boneka yang ada dalam ruangan sudah menjadi pasien dengan keluhan yang berbeda-beda, peneliti dalam k4 memberikan dua keluhan psikosomatis. Perubahan fisik yang tampak pada permainan ini adalah postur tubuh dan ekspresi wajah $\mathrm{S}$ tampak lebih santai. Peneliti merasa $S$ telah memiliki penerimaan dan uraian tentang konsep ayah dalam hidupnya. Sesi 5. Peneliti meminta $S$ menggambarkan rumah-pohon-orang, goresan garis terlihat lemah. Lalu $\mathrm{S}$ bermain boneka tangan dan pasir, dan memasang perabot rumah-rumahan (k3) dalam hening, dengan pergerakkan tangan yang terlihat bergetar dan terasa dingin. Sesi 6. S menata rumah dan memastikan semua figur dalam rumahnya memiliki aktivitas, terlihat ada komunikasi, dan terasa nyaman (k3). S kemudian sibuk memilih kostum dan balok (k3), dan kemudian peneliti memintanya menggambarkan bunga dan tampak ada 2 jenis bunga yang bertolak belakang jenisnya yaitu pohon kaktus dan bunga matahari.

Hening adalah tema dalam periode ini $\mathrm{S}$ banyak berproses dalam $\mathrm{k} 3$, dan terapis berperan sebagai reflektor. Peneliti melihat $S$ mulai dapat berpikir tentang eksistensinya dalam keluarga dan lingkungan sosialnya, dalam rumah boneka sesi keenam terlihat hubungan yang positif. Dalam art, $\mathrm{S}$ tampak mulai mengenali konfliknya.

Sesi 7. Peneliti meminta S menggambar dalam lingkaran (k4) dengan arahan dan kemudian membuat cetakan kedua tangannya sambil bercakap dengan jari-jarinya, dan kemudian sepenuhnya memberikan S kesempatan untuk memproses kedua tangannya. Tampak bahwa $\mathrm{S}$ memberikan upaya lebih besar dan lebih serius untuk mewarnai tangan kirinya (k4). S bermain pasir basah, dan mengosongkan bagian kiri pasir dengan tenaga yang besar, dan untuk pertama kalinya $\mathrm{S}$ bercerita panjang lebar tentang berbagai pengalamannya, terutama perilaku yang tidak disengaja dilakukannya pada Gurunya (k1). Peneliti melihat S memiliki kecemasan dan ketakutan untuk melakukan kesalahan. Sesi 8. Untuk pertama kalinya S percaya diri untuk berbicara dengan Bahasa Inggris dan memilih relaksasi dengan bubbles (k3). S berani mengatakan tidak suka pada bentuk mainan yang peneliti ujikan dan memilih yang dia suka (k2). Sesi 9. Diawal sesi S memilih tanah liat dan membuat manusia salju lalu bermain bubbles ((k3), dan kemudian peneliti memberikan ide meniup bubbles. Lalu berinisiatif mengumpulkan figur dalam film animasi kartun Moana dan Frozen sebagai satu kesatuan (k1). Pada akhir sesi ini S menunjukkan ekspresi sedih karena waktu bermain habis. Peneliti melihat $\mathrm{S}$ mulai dapat lebih tenang. Dalam periode ini, S mulai berkomunikasi secara verbal menguraikan pengalamannya, dapat menentukan pilihan, $S$ mulai memiliki keberanian menggunakan Bahasa Inggris walaupun masih berantakan, tampak memiliki ekspresi wajah dan pergerakan tubuhnya lebih santai. S dapat memproses kembali pengalamannya dengan Guru mulai dapat memilah dan mengelompokkan figur (categorization), dalam fase concrete operational stage (Papalia \& Feldman, 2012). Peneliti melihat proses healing terjadi melalui Art therapy pada sesi 7, salah satu tanda fisik yang ditemukan oleh peneliti adalah perubahan suhu tangan S, tidak lagi terasa dingin. Sesuai dengan temuan Adamson, salah seorang pioneer art therapy di London bahwa saat seseorang mendapatkan kesempatan untuk mengekspresikan dirinya dalam art tanpa intervensi maka orang tersebut dapat mengalami healing (O’Flynn, 2016). 
Di akhir sesi ke 7, Ibu S memberikan informasi "sekarang ini kalau mau ke sekolah sudah lancar. Kecemasannya masih ada, hanya sekarang bisa ditenangin". Di akhir sesi ke 9, Ibu S memberikan informasi bahwa $S$ tidak menangis saat ada suara yang tinggi dan saat mengalami kesulitan belajar, sudah bisa bercerita tentang macam-macam pengalamannya di sekolah. Biasanya kalau melakukan perilaku yang salah dan tidak sengaja sekalipun akan dipikirkan lama sekali dan mogok sekolah, tetapi sekarang tetap mau sekolah. Di kelas tidak memerlukan pengulangan instruksi karena takut salah tetapi akan bertanya dan memastikan dia mengerjakan dengan benar. Sudah lebih berani menjawab pertanyaan orang yang masih baru di kenal walaupun dengan suara kecil. Di tempat bermain, jika ada anak lain yang lebih besar mengajak bermain, maka $\mathrm{S}$ akan ikut bermain tetapi masih non-verbal, tetapi jika anak lain yang lebih kecil mengajak bermain, maka $S$ akan akan main dan berbicara.

Sesi 10. S menikmati aktivitas meniup bubbles (k3). Peneliti menawarkan $\mathrm{S}$ melukis bubles yang menurutnya berwarna pelangi sambil bercerita tentang warna kesukannya, dan bagaimana sikapnya di mall (k4). Mewarnai dan menghias tangan kanannya (k4). Peneliti melihat S memiliki kebutuhan yang besar untuk relaksasi. Sesi 11. S menggerakkan semua tangannya, semua figur dalam rumah boneka terlihat sibuk tetapi terasa menyenangkan, memilih boneka tangan berbentuk jari (k3). Peneliti melihat S mulai dapat memahami perspektif orang lain dan mulai dapat berempati. Sesi 12. Peneliti menceritakan sebuah cerita terapetik dalam konsep Freudian (id/ego/super-ego), sambil S bermain pasir. Setelah cerita habis, $\mathrm{S}$ mengatakan apa yang dibuatnya (k4). S menjadi kupu dan burung, peneliti diminta menjadi landak dan rubah yang mengeluh karena tidak bisa terbang, dan S berkata "kalian harus bersyukur menjadi rubah dan landak" (k4).

Sesi 13. S mencari boneka jari dan meminta peneliti menceritkan kisah tiga babi kecil (k3). Lalu $\mathrm{S}$ berperan menjadi kupu-kupu cantik, baik hati, dan mau berteman dengan siapa saja dan bubbles (k3). Peneliti melihat S sebagai sosok yang lebih memiliki kepedulian dan memiliki pendirian. Sesi 14. Sepanjang sesi ini $\mathrm{S}$ berpose menjadi peri dengan tongkat ajaib dan boneka tangan sebagai dokter (k4). Sesi 15. S berinisiatif ingin jadi superhero dengan kostum-kostum yang tersedia (k3) dan kemudian bermain menjadi pembuat kue, sambil bercerita tentang mainannya di masa kecil (k3). S tampak memiliki kebutuhan untuk lebih mengekspresikan dirinya. Di akhir sesi 14, Ibu memberikan informasi "S sekarang ini lebih banyak cerita, sekarang jauh lebih berani". "Aku khan beliin buku gambar A3, sekarang ini mau gambar-gambar, tapi gambarnya masih itu-itu saja, contoh rumah dan sekitarnya. S mau mewarnai satu buku habis, biasanya ngga pernah gitu. Kalo bercanda dari dulu ekspresif mukanya sama orang di rumah, tapi kalo sama orang lain lurus-lurus, nah sekarang kalo sama orang lain lebih bisa mengungkapkan”.

Sesi 16. Pada awal sesi peneliti memberikan 'reminder' bahwa special time akan berakhir pada sesi 18. S sibuk membuat kue, menamai kue, dan meminta tamu memesan kuenya tetapi tidak suka pada singa (k3) dan kemudian bermain petak umpet (boneka) (k3). S menyembunyikan tangannya dibawah pasir (k3). Peneliti melihat S memiliki kecemasan karena special time akan berakhir dan mempersiapkan dirinya. Sesi 17. Dalam rumah boneka, S tampak ingin sekali dapat bersosialisasi dengan orang lain (bukan keluarga), tetapi mengharapkan peneliti membuka komunikasi (k4). Peneliti melihat ada kemungkinan S kurang mendapatkan eksposure sosial selain dengan keluarganya. Sesi 18. S mengerti ini adalah akhir special time, berbeda dari biasanya S memilih sebuah buku dan meminta peneliti membacanya, lalu dia mengambil buku lain dalam Bahasa Inggris dan membacanya bagi peneliti, dengan suara yang keras (k1). S memilih permainan yang membutuhkan kecekatan tangan, kreativitas, dan kecekatan (k3). Dalam periode ini tangan S tidak lagi terasa dingin, dan pada sesi $18 \mathrm{~S}$ menampilkan dirinya dengan percaya diri, berani berbicara dengan ekspresi, memiliki inisiatif untuk mencoba jenis mainan baru yang membutuhkan 
kreativitas dan kecekatan tangan. Di akhir sesi 18, Ibu S mengatakan bahwa "sosialisasi S lebih baik di sekolah dan bisa bermain di komplek rumah. S membuat peta di sekolah dan membuat surat buat Ayah dan Ibunya "I love You Ibu dan Ayah - You are my heroes". Ibu S menyatakan bahwa semua yang diharapkan dari CCPT sudah tercapai. Pada bulan Maret dan Mei 2019, Ibu memberi informasi bahwa $\mathrm{S}$ terus bersemangat sekolah dan berani untuk tampil di depan kelas. Perubahan perilaku tersebut didukung dengan perbedaan skor pre-test(22) dan post-test(10) pada sub-scales, hyperactive, emotion, conduct, dan peers, pada alat ukur strength and difficulties questionaires mendukung hasil penelitian single case study ini.

Tabel 1

Perbedaan Skor Pre Test Dan Pos Test

\begin{tabular}{lcccccc}
\hline SDQ Scales & Prososial & Hyperactive & Emotion & Conduct & Peers & Total \\
Pre/Post - & $2 / 9$ & $5 / 3$ & $7 / 3$ & $7 / 2$ & $3 / 2$ & $22 / 10$ \\
Test Skor & & & & & & \\
\hline
\end{tabular}

\section{Pembahasan}

Dalam penelitian ini perilaku menolak sekolah tampak disebabkan oleh kesulitan S memproses masalah emosionalnya secara internal maupun eksternal sehingga terjadi repression. Repression umumnya terjadi saat anak-anak terluka secara emosional kemudian berusaha menutup ingatan tersebut, tetapi ingatan tersebut tidak hilang dan mempengaruhi diri mereka dalam bentuk kecemasan atau kemarahan di tahap perkembangan selanjutnya (Ehrenfeld, 2015). Pengalaman anak bermain dalam CCPT bersifat terapetik (Axline, 1969), dan saat bermain anak-anak akan mendemonstrasikan kemampuan mereka untuk berkomunikasi dan mengeksplorasi hubungan interpersonal mereka dengan orang dewasa lain dan lingkungan sosialnya (Jennings, 1999).

Pada sesi 1-3, S memproses konsep ayah dalam hidupnya dan konflik dalam dirinya dengan media tanah liat. Tanah liat adalah elemen bumi, yang merepresentasikan realitas dan insting, dan dalam proses terapetik dinilai sebagai forgiving medium yang secara langsung menjadi mediasi perasaan dan emosi (Anderson, 2010). Setelah sesi ke-3, S mau pergi ke sekolah tanpa menangis. Pada sesi 4-6, S banyak berproses dalam keheningan, situasi hening memampukan $\mathrm{S}$ untuk memproses masalahnya lebih dalam. Menurut Jennings (1999), banyak anak-anak membutuhkan waktu hening dalam bermain untuk melakukan refleksi. Dalam hening sekalipun, Axline (1949) tetap meyakini bahwa anak tetap berproses, dan terapis tidak diijinkan untuk mempercepat proses terapetik, sebab anak mengerti hal yang mereka butuhkan dalam prosesnya dan kapan mereka siap bergerak ke proses selanjutnya. Pada sesi 7-9, S tampak mengalami self-healing, melalui aktivitas meniup bubbles dan bermain pasir. Thorne (2016) menemukan dalam praktiknya bahwa aktivitas meniup bubbles dalam sesi CCPT mengembangkan personal boundaries dan pola hubungan interpersonal yang sehat. Menurut Weinrib (2004), pasir memfasilitasi proses terapetik dan meditatif. Texture alami pasir secara simbolik mampu menyerap energi negatif dan memberikan relaksasi.

Pada sesi 10-12, S bermain untuk mengembangkan self-expression, self-actualization, dan komunikasi. Peneliti melihat ada perubahan perilaku yang positif yang disebut dengan pride, gratitude, love, curiosity and playfulness (Gallagher \& Lopez, 2007; in King, 2016), perubahan perilaku S sesuai dengan tujuan CCPT. Pada sesi 13-15. S memiliki kepercayaan diri untuk mengembangkan self-mastery, kompetensi, dan kreativitas melalui aktivitas drama, bermain peran dan story telling. Mendukung temuan Jennings sebelumnya (1999) bahwa saat individu mendapatkan makin banyak eksposure terhadap theater art, maka akan makin mampu menceritakan pengalamannya secara dramatik dam proses terapetik terjadi saat terapis dan anak terlibat dalam aktivitas drama yang bersifat imaginatif. Bermain sebagai orang lain membuka dan memperluas perspektif dan pemahaman anak yang berguna sebagai dasar dari perkembangan 
sosial (O'connor, 2000; in Yasenik \& Gardner, 2012). Pada sesi 16-18, transformasi perubahan perilaku $\mathrm{S}$ terlihat jelas dan semua harapan Ibu terpenuhi.

Laporan observasi peneliti menunjukkan bahwa S menunjukkan perubahan perilaku pada sesi ke delapan di mana S percaya diri untuk berbicara menggunakan Bahasa Inggris. Laporan orangtua di akhir sesi ke sembilan memperkuat laporan observasi peneliti pada sesi 8. Sesi ke tujuh tampak menjadi kunci perubahan perilaku S, dimana permainan yang digunakan dalam sesi ini adalah media art. Media art banyak digunakan sebagai bentuk intervensi yang memfasilitasi hubungan antara tubuh dan pikiran, mengendurkan tingkat stres sehingga dapat mengubah persepsi otak terhadap faktor pemicu stres (Cohen dalam Cohen \& Carr, 2008).

Proses terapetik $\mathrm{S}$ banyak terjadi dalam k3/non-intrusive responding dan k4/co-facilitation. Dalam k3 dan k4 anak memiliki ruang dan kebebasan untuk mengenali, menerima, mengeksplorasi dirinya, dan bertanggung jawab pada dirinya. (Fleet, Sywulak, \& Sniscak, 2010). Dalam k3, S mengatualisasikan dirinya dengan kebebasan untuk memilih jenis dan model permainannya untuk memproses masalah emosionalnya dan peneliti dapat bermain bersama dengan anak jika diminta dan sepenuhnya mengikuti arahannya dan memiliki lebih banyak kesempatan untuk mengamati $\mathrm{S}$ dan memberikannya kepercayaan untuk memproses masalahnya secara intrinsik Proses terapetik dalam k3 memberikan peniliti kesempatan untuk dapat memahami pikiran, perasaan, dan pengalaman S, melalui permainannya (Yasenik \& Gardner, 2012). Proses terapetik dalam k4, membuka jalan baru bagi $\mathrm{S}$ untuk memproses emosinya, dan peneliti dapat menyatu dalam permainannya serta memberikan figur/ide/media alternatif dalam aktivitas bermain (Landreth, 2002; Wilson et al., 1992; dalam Yasenik \& Gardner, 2012).

Dalam kasus ini, pendekatan person-centered yang mengacu kepada unconditional acceptance dan empathetical listening, memampukan terapis untuk melihat $\mathrm{S}$ sebagai individu yang memiliki kapasitas personal untuk menyelesaikan masalahnya. Play therapy, memberikan ruang dan kesempatan pada $\mathrm{S}$ untuk memproses masalah yang sulit untuk diekspresikan dalam kata-kata kedalam bentuk art maupun permainan, dalam batasan yang aman. Dalam kasus S, perubahan perilaku menolak sekolah menjadi mau sekolah, terjadi dalam beberapa tahapan, (1) $S$ dapat mengenali dan mengekspresikan konflik internal yang dialaminya; (2) S memproses masalahnya dalam keheningan; (3) S melepaskan ketegangannya dengan relaksasi; (4) S mengembangkan kompetensi dirinya; (5) S berlatih untuk mengekspresikan dirinya dalam permainan; (6) S percaya diri untuk mengaktualisasikan dirinya. Keberhasilan penelitian ini didukung oleh bukti-bukti empiris, tetapi hasilnya tidak dapat digeneralisasikan karena penerapannya terbatas hanya pada sebuah kasus saja. Peneliti berharap ada beberapa penelitian lain yang mengulas dinamika proses CCPT untuk mengatasi kasus perilaku menolak sekolah. Di akhir sesi, S terlihat memiliki rasa percaya diri, tidak menangis saat ada orang lain tertawa padanya, rasa cemas dan takutnya berkurang, dan memiliki rasa kompetitif.

\section{KESIMPULAN DAN SARAN}

Dalam penelitian single case study ini, child-centered play therapy (CCPT) terbukti dapat mengatasi perilaku menolak sekolah dengan cara yang menyenangkan dan aman bagi anak. S tidak lagi menangis saat mau tidur malam dan saat bangun pagi, $\mathrm{S}$ sudah tidak lagi mengatakan tidak mau sekolah, melekat/clingy, cemas, menangis, dan somatis. Data empiris yaitu laporan observasi peneliti, dokumentasi sesi, sejalan dengan laporan orangtua dalam memberikan gambaran tentang perubahan emosi dan perilaku partisipan. Perubahan yang dialami oleh partisipan sejalan dengan tujuan utama child-centered play therapy (Jennings, 1999) yaitu self-healing dan well-being dan mendukung temuan Sweeney \& Landreth dalam Schaefer (2011) yaitu untuk meningkatkan aktualisasi diri secara lebih positif, kemampuan memilih, kepercayaan diri, dan sense of mastery. Secara spesifik $C C P T$ telah memfasilitasi perubahan perilaku yang diharapkan oleh orangtua $\mathrm{S}$ di awal. Pada up-date informasi yang diberikan oleh ibu pada bulan Mei 2019, S pernah menolak 
sekolah, karena belum merasa siap untuk ujian. Namun, setelah $\mathrm{S}$ didampingi untuk mempersiapkan ujian beberapa hari sebelumnya, S tidak lagi menolak sekolah sekalipun ujian. Perhatian dan keperdulian ibu menjadi salah satu faktor penting terhadap perubahan perilaku menolak sekolah S. Temuan ini mendukung eksistensi CCPT sebagai alternatif intervensi konvensional yang umumnya bersifat direktif $C C P T$ dapat dipertimbangkan sebagai metode untuk membantu anak-anak yang mengalami represi emosional dalam perkembangnnya.

\section{Ucapan Terima Kasih}

Terimakasih kepada partisipan yang telah terlibat dalam penelitian ini, serta pihak-pihak yang mendukung terwujudnya penulisan karya ilmiah ini. Khususnya Bapak Monty P Satiadarma dan Ibu Naomi Soetikno yang telah menginspirasi dan memotivasi kami.

\section{REFERENSI}

Anderson, L, S. (2010). Touching Clay, Touching What? The Use of Clay in Therapy. Archive Publishing: England.

Axline, V. M. (1969). Play Therapy. USA:Balantine Books.

Busman, R. (2018). When Kids refuse to go to school.childmind.org https://childmind.org/article/when-kids-refuse-to-go-to-school/

Bean, S. (2018). "I Hate School!" What Can I Do When My Child Refuses to Go to School? https://www.empoweringparents.com/article/hate-school-can-child-refuses-go-school/

Beesdo, K., Knappe, S., \& Pine, D, S. (2009). Anxiety and Anxiety Disorders in Children and adolescents: Developmental Issues and Implications for DSM-V. Psychiatr Clin North Am. 32(3): 483-524. https://dx.doi.org/10.1016\%2Fj.psc.2009.06.002

Carter, S. Managing Anxiety in Children. https://www.lianalowenstein.com/article_carter.pdf

Cohen, N. H., \& Carr. R. (2008). Art Therapy and Clinical Neuroscience. Jessica Kingsley publishers: London and Philadelphia.

Campbell M. (2007). Innovative counselling with anxious children. Counselling, Psychotherapy, and Health, 3(1), 59-70. https://www.researchgate.net/publication/27469551_Innovative_counselling_with_anxio us_children

Ehrenfeld,T.(2015). We Don't Repress Childhood Memories. Psychologytoday. https://www.psychologytoday.com/us/blog/open-gently/201504/we-dont-repress-painfulchildhood-memories

Frankel, T, C. (2018). Child's Play: How Play Therapy Works. Kids can't always put their feelings into words. The Contemporary Psychoanalysis Group. Psychologytoday.com https://www.psychologytoday.com/us/blog/contemporary-psychoanalysis-inaction/201601/child-s-play-how-play-therapy-works

Fennel, F. (2016). Practitioner Paper: Is the Sand Tray a Beneficial Therapeutic Approach for Children with an Anxiety Disorder. Play For Life. p.11.

Fleet, R. V., Sywulak, A. E., \& Sniscak, C. C. (2010). History, Theory, Principles, and variations of child-centered Play Therapy. Guilford Publications.

Feist, J., Feist, G, J., \& Roberts, T-A. (2009). Theories of Personality. McGraw-Hill: NY.

Fremont, W. P. (2003). School refusal in children and adolescents. American Family Physician, 68(8), 1555-1561. https://www.aafp.org/afp/2003/1015/p1555.html

Hanurawan, F. (2016). Metode Penelitian Kualitatif Untuk Ilmu Psikologi. PT RajaGrafindo Jakarta.

Howitt, D. (2010). Introduction to Qualitative Research Methods in Psychology. Pearson Education. 
Jennings, S. (1999). Introduction to Developmental Playtherapy. Jessica Kingsley Publishers: UK \& USA

King, J. L. (2016). Art Therapy, Trauma, and Neuroscience: Theoritical and Practical Perspective. routledge, Taylor and Francis Group: NY \& London

Kaduson, H, G. (2006). Release Play Therapy for Children with Posttraumatic Stress Disorder. Guilford publication.https://www.guilford.com/excerpts/kaduson_old.pdf

Kearney, C, A., \& Albano, A, M. (2007). When Children Refuses School: A Cognitive Behavioral therapy Approach. Oxford University Press https://www.oxfordclinicalpsych.com/view/10.1093/med:psych/9780195308297.001.000 $1 \quad$ /med- 9780195308297

Kearney, C. A. (2006). Dealing with school refusal behavior: A primer for family physicians. Journal of Family Practice, 55, 685-692.

Kearney, C. A., Chapman, G., \& Cook, L. C. (2005). School refusal behavior in young children. International Journal of Behavioral Consultation and Therapy, 1(3), 216-222. https://dx.doi.org/10.1037/h0100746. http://psycnet.apa.org/fulltext/2014-45640-004.html

Kaduson, H, G., \& Schaefer, C, E. (2006). 2nd. Short-Term Play Therapy for Children. Guilford publication. https://www.guilford.com/excerpts/kaduson_old.pdf

Lingenfelter, N., \& Hartung, S. (2015). School Refusal Behavior. NASN School Nurse, 30(5), 269-273. doi:10.1177/1942602x155701

Lok, C. (2016). The efficacy of individual and non-directive play therapy on Chinese children with anxiety disorder. International Journal of Play and Creative Arts Therapies 1(1).

Mullen, J, A., \& Rickli, J, M. (2014). Child Centered Play Therapy Workbook. Research Press Publishers, Illinois.

O’Flynn, D. (2016). Art as Healing: Edward Adamson. http://www.adamsoncollectiontrust.org/wp-content/uploads/2016/09/2-2011.-DOF-RawVision- for-EAF.pdf

Papalia, D. E., \& Feldman, R. D. (2012). 12th. Experience Human Development. The MacGrawHill: NY

raisingchildren.net.au. (2016). School refusal: children 5-8 years. The Australian Parenting https://raisingchildren.net.au/school-age/school-learning/school-refusal/school- refusal

Schaefer, C, E. (2011). Foundations of Play Therapy. John Wiley \& Sons, Inc.

Thorne, D. (2016). Practitioner Paper: The Supper Bubble Popper; how bubbles develop personal boundaries and healthy connective styles within a dynamic approach to play therapy.

Waller, D. (2006). Art Therapy for Children: How It leads to Change. Clinical Child Psychology and Psychiatry.

https://www.researchgate.net/publication/6709804_Art_Therapy_for_Children_How_It_ Leads_to_Change

Young, J, L. (2017). Understanding School Refusal. Psychologytoday.com https://www.psychologytoday.com/us/blog/when-your-adult-child-breaks-yourheart/201709/understanding-school-refusal

Yasenik, L., \& Gardner, K. (2012). Play Therapy Dimensions Model. Jessica Kingsley Publisher: UK. 